University of South Carolina

Scholar Commons

1993

\title{
Impedance Analysis for Oxygen Reduction in a Lithium Carbonate Melt: Effects of Partial Pressure of Carbon Dioxide and Temperature
}

\author{
Bhasker B. Dave \\ Texas A \& M University - College Station \\ Ralph E. White \\ University of South Carolina - Columbia, white@cec.sc.edu \\ Supramaniam Srinivasan \\ Texas A \& M University - College Station \\ A. John Appleby \\ Texas A \& M University - College Station
}

Follow this and additional works at: https://scholarcommons.sc.edu/eche_facpub

Part of the Chemical Engineering Commons

\section{Publication Info}

Journal of the Electrochemical Society, 1993, pages 2139-2145.

(c) The Electrochemical Society, Inc. 1993. All rights reserved. Except as provided under U.S. copyright law, this work may not be reproduced, resold, distributed, or modified without the express permission of The Electrochemical Society (ECS). The archival version of this work was published in the Journal of the Electrochemical Society.

http://www.electrochem.org/

Publisher's link: http://dx.doi.org/10.1149/1.2220786

DOI: $10.1149 / 1.2220786$

This Article is brought to you by the Chemical Engineering, Department of at Scholar Commons. It has been accepted for inclusion in Faculty Publications by an authorized administrator of Scholar Commons. For more information, please contact digres@mailbox.sc.edu. 


\title{
Impedance Analysis for Oxygen Reduction in a Lithium Carbonate Melt: Effects of Partial Pressure of Carbon Dioxide and Temperature
}

\author{
Bhasker B. Dave*,a and Ralph E. White ${ }^{*, b}$ \\ Center for Electrochemical Engineering, Department of Chemical Engineering, Texas A\&M University, \\ College Station, Texas 77843 .
}

\section{Supramaniam Srinivasan* and A. John Appleby*}

Center for Electrochemical Systems and Hydrogen Research, Texas A\&M University, College Station, Texas 77843

\begin{abstract}
Effects of partial pressure of carbon dioxide and temperature on oxygen reduction kinetics on a gold electrode in a lithium carbonate melt were examined using electrochemical impedance spectroscopic (EIS) and linear sweep voltammetric techniques. The impedance spectra were analyzed by a complex nonlinear least squares method, using the RandlesErshler equivalent circuit model, to determine the electrode-kinetic and the mass-transfer parameters such as the chargetransfer resistance and the Warburg coefficient. The cyclic voltammetric measurements indicated that the oxygen reduction process in lithium carbonate melt is "reversible" up to $200 \mathrm{mV} / \mathrm{s}$. The product $D_{0}^{1 / 2} C_{0}$ determined by cyclic voltammetry agreed well with those estimated by the EIS method. The reaction order with respect to carbon dioxide and the activation energy for the exchange current density were determined to be -0.52 and $132 \mathrm{~kJ} / \mathrm{mol}$, respectively. Also, the reaction order with respect to carbon dioxide and the activation energy for $D_{0}^{1 / 2} C_{0}$ were calculated to be -0.8 and 185 $\mathrm{kJ} / \mathrm{mol}$, respectively.
\end{abstract}

The oxygen reduction reaction in molten alkali carbonate electrolytes has been studied for the past quarter century because of its vital role in the performance of the molten carbonate fuel cell. Borucka and Sugiyama ${ }^{1,2}$ studied the $\mathrm{O}_{2} / \mathrm{CO}_{2} / \mathrm{Au}$ electrode in a ternary $[43.5$ mole percent (m/o) Li:31.5 m/o Na:25.0 m/o] $\mathrm{CO}_{3}$ eutectic melt in the temperature range of $550-800^{\circ} \mathrm{C}$ and concluded the following: $(i)$ the effects of the partial pressures of oxygen and carbon dioxide on the equilibrium potential show that the overall reaction at equilibrium is

$$
1 / 2 \mathrm{O}_{2}+\mathrm{CO}_{2}+2 e^{-} \leftrightarrow \mathrm{CO}_{3}^{2-}
$$

and the equilibrium potential obeys the Nernst equation

$$
E_{\mathrm{O}_{2}, \mathrm{CO}_{2} / \mathrm{CO}_{3}^{2-}}=E_{\mathrm{O}_{2}, \mathrm{CO}_{2} / \mathrm{CO}_{3}^{2-}}^{0}+\frac{R T}{n F} \ln \left(P_{\mathrm{O}_{2}}^{1 / 2} P_{\mathrm{CO}_{2}}\right)
$$

(ii) the micropolarization tests at near-equilibrium indicate that the electrode is under "mixed" control, due to charge-transfer and the mass-transport processes, even close to the equilibrium potential; and (iii) the exchange current density for the electrode reaction (Eq. 1) is about $0.1 \mathrm{~mA} / \mathrm{cm}^{2}$. Appleby and Nicholson ${ }^{3-6}$ examined the oxygen reduction reaction in molten carbonates on a submerged gold electrode using stready-state and potentialscan techniques. They observed that oxygen reacts with carbonate ions and forms peroxide and/or superoxide ions and the concentrations of these species depend on the cations present in the melt. In a pure $\mathrm{Li}_{2} \mathrm{CO}_{3}$ or a $\mathrm{Li}$-rich melt the peroxide species are dominant, whereas in a $\mathrm{K}$ rich melt the superoxide species are dominant. Appleby and Nicholson proposed the following reaction mechanism for oxygen reduction in pure lithium carbonate melt

$$
\begin{gathered}
1 / 2 \mathrm{O}_{2}+\mathrm{CO}_{3}^{2-} \leftrightarrow \mathrm{O}_{2}^{2-}+\mathrm{CO}_{2} \\
\mathrm{O}_{2}^{2-}+e^{-} \leftrightarrow\left(\mathrm{O}^{-}\right)+\mathrm{O}^{2-} \\
\left(\mathrm{O}^{-}\right)+\mathrm{CO}_{2}+e^{-} \leftrightarrow \mathrm{CO}_{3}^{2-} \\
\mathrm{O}^{2-}+\mathrm{CO}_{2} \leftrightarrow \mathrm{CO}_{3}^{2-}
\end{gathered}
$$

The overall reaction is

$$
1 / 2 \mathrm{O}_{2}+\mathrm{CO}_{2}+2 e^{-} \leftrightarrow \mathrm{CO}_{3}^{2-}
$$

* Electrochemical Society Active Member

a Present address: Nalco Chemical Company, Naperville, Illinois 60563 .

${ }^{b}$ Present address: University of South Carolina, Columbia, South Carolina 29208. where $\left(\mathrm{O}^{-}\right)$is a transient species. According to this reaction mechanism, the first charge-transfer step (Eq. 4) is the rate-determining one for an immersed electrode. Appleby and Nicholson also examined the oxygen reduction in binary $(47 \mathrm{~m} / \mathrm{o} \mathrm{Li}: 53 \mathrm{~m} / \mathrm{o} \mathrm{K}$ and $43 \mathrm{~m} / \mathrm{o} . \mathrm{Na}: 57 \mathrm{~m} / \mathrm{o} \mathrm{K})$ and ternary $(43.5 \mathrm{~m} / \mathrm{o} \mathrm{Li}: 31.5 \mathrm{~m} / \mathrm{o} \mathrm{Na}: 25 \mathrm{~m} / \mathrm{o} \mathrm{K})$ eutectics in the temperature range of $700-800^{\circ} \mathrm{C}$ and concluded that: $(i)$ the electroactive species is not the oxygen molecule; $(i i)$ both peroxide and superoxide ions are present and are reduced in the parallel steps; and (iii) the neutralization of the oxide ions by carbon dioxide (Eq. 6) is slow. Andersen ${ }^{7}$ carried out a thermodynamic study on the chemical equilibria in molten alkali carbonate electrolytes and demonstrated the presence of peroxide ions in quenching experiments followed by chemical analyses. Appleby and Van Drunen ${ }^{8}$ determined the total solubility of oxygen species (mainly in the form of peroxide and superoxide ions) in molten carbonate electrolytes as a function of temperature using quenching method. Vogel et al. ${ }^{9}$ studied the (Li-K) $\mathrm{CO}_{3} \mathrm{eu}-$ tectic melt at $650^{\circ} \mathrm{C}$, using a rotating gold wire and concluded that superoxide is dominant in this melt and the concentration of molecular oxygen in the melt is negligible. Smith et $a l .{ }^{10}$ determined the total solubility of oxygen species in (Li-Na-K) $\mathrm{CO}_{3}$ eutectic melt as a function of gas composition at $650^{\circ} \mathrm{C}$, using a chemical method. They con-

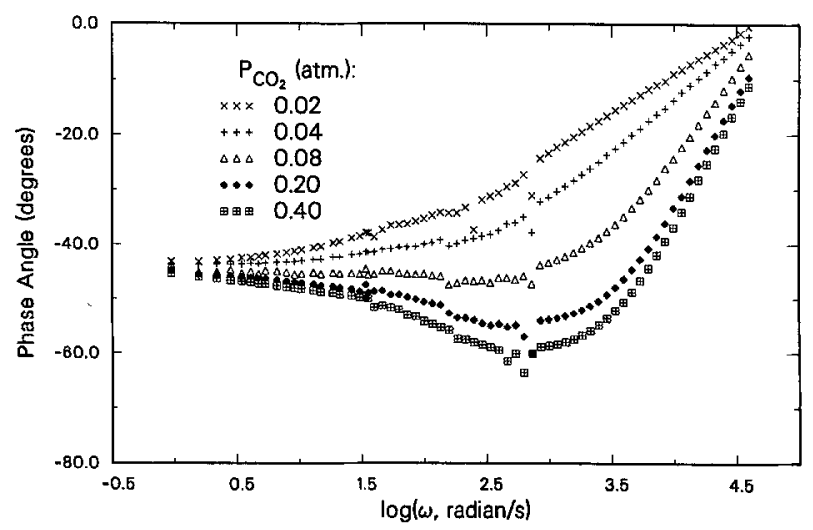

Fig. 1. Phase angle vs. $\log \omega$ plot as a function of $\mathrm{PCO}_{3}$ for $\mathrm{O}_{2}$ reduction on gold electrode in $\mathrm{Li}_{2} \mathrm{CO}_{3}$ melt at $0.6 \mathrm{~atm} . P_{\mathrm{O}_{2}}$ and $800^{\circ} \mathrm{C}$. 


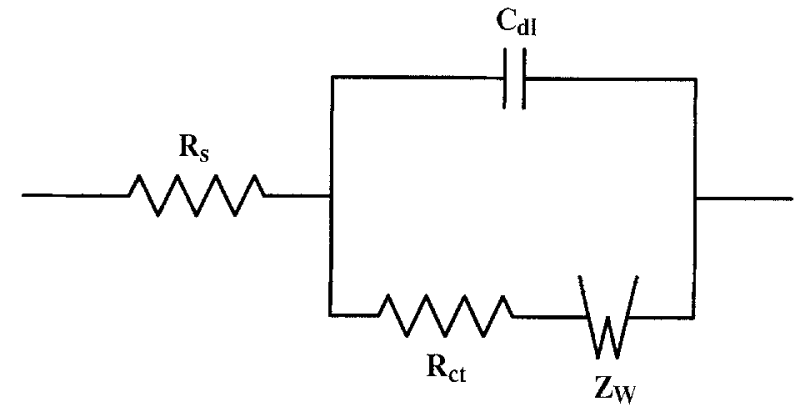

$\mathbf{R}_{\mathrm{s}}=$ Solution Resistance, $\Omega \mathrm{cm}^{2}$

$\mathbf{R}_{\text {ct }}=$ Charge Transfer Resistance, $\Omega \mathbf{c m}^{2}$

$\mathrm{C}_{\mathrm{dl}}=$ Double Layer Capacitance, Farad $\mathrm{cm}^{-2}$

$\mathrm{Z}_{\mathrm{W}}=$ Warburg Impedance, $\Omega \mathrm{cm}^{2}$

Fig. 2. The Randles-Ershler equivalent circuit model to represent the interfacial impedance for oxygen reduction on gold in lithium carbonate melt.

cluded that oxygen reacts with $(\mathrm{Li}-\mathrm{Na}-\mathrm{K}) \mathrm{CO}_{3}$ melt at $650^{\circ} \mathrm{C}$ to form superoxide ions and the concentration of physically dissolved, molecular, oxygen is negligible. Dunks and Stelman $^{11}$ studied the oxygen reduction mechanism in a pure sodium carbonate at $900^{\circ} \mathrm{C}$ using cyclic voltammetry and computer-curve fitting and proposed the existence of percarbonate ions. They also confirmed the presence of superoxide ion in the frozen electrolyte by electron spin resonance (ESR) spectrum at $77 \mathrm{~K}$. $\mathrm{Lu}^{12}$ investigated oxygen reduction kinetics in pure $\mathrm{Li}_{2} \mathrm{CO}_{3}$ and a $\mathrm{Li}-\mathrm{K}(62 \mathrm{~m} / \mathrm{o}$ : $38 \mathrm{~m} / \mathrm{o}$ ) carbonate eutectic mixture using the potential step method. The exchange current density, determined by $\mathrm{Lu}$ $\left(39 \mathrm{~mA} / \mathrm{cm}^{2}\right.$ for $90 \% \mathrm{O}_{2}$ and $10 \% \mathrm{CO}_{2}$ at $750^{\circ} \mathrm{C}$ in $\mathrm{Li}_{2} \mathrm{CO}_{3}$ melt), is two orders of magnitude higher than that reported by Appleby and Nicholson $\left(0.34 \mathrm{~mA} / \mathrm{cm}^{2}\right)$, who used the potential scan technique. But the dependence of oxygen reduction kinetics on partial pressures of oxygen and carbon dioxide observed by Lu could not be explained by any mechanism proposed in the literature. Uchida et al. ${ }^{13}$ determined the electrode kinetic parameters for oxygen reduction on a gold electrode in a $(\mathrm{Li}-\mathrm{K}) \mathrm{CO}_{3}(42.7 \mathrm{~m} / \mathrm{o}$ : $57.3 \mathrm{~m} / \mathrm{o}$ ) eutectic melt using impedance analysis, potential step, and coulostatic relaxation techniques. They found that the exchange current density was about the same order of magnitude as that reported by Lu. In addition, they concluded that of the three methods for the determination of the electrode kinetic parameters for oxygen reduction in molten carbonates the impedance analysis is the most reliable. Uchida et al. used the Randles-Ershler equivalent circuit model to analyze the impedance data for oxygen reduction in molten carbonates. Uchida et al. ${ }^{14}$ examined the oxygen reduction on a lithiated $\mathrm{NiO}$ film, deposited on gold, and $\mathrm{Sb}$-doped $\mathrm{SnO}_{2}$ electrodes in Li-K eutectic melt by impedance spectroscopy and coulostatic relaxation techniques. They ${ }^{15}$ also determined the temperature dependence of the electrode-kinetic and mass-transfer related parameters for oxygen reduction on gold in (Li$\mathrm{K}) \mathrm{CO}_{3}$. Adanuvor et $a l .{ }^{16}$ simulated the oxygen reduction reaction in various alkali carbonate melts; this mathematical model considered the simultaneous presence of peroxide and superoxide ions with slow neutralization reaction. Ramaswami ${ }^{17}$ used a rotating disk electrode made of gold to study the oxygen reduction reaction in a pure lithium carbonate melt at $800^{\circ} \mathrm{C}$ and determined the diffusion coefficient and peroxide ion concentration as a function of the partial pressure of oxygen. The diffusion coefficient was found to be independent of the concentrations of the peroxide ions. Ramaswami also determined the rate constant of the recombination reaction (Eq. 6) by the analysis of the potential response to oxide addition. Nishina and Uchida ${ }^{18}$ investigated the oxygen reduction mechanism in molten carbonate electrolytes by electrochemical impedance spectroscopy. They used Randles-Ershler equivalent circuit for

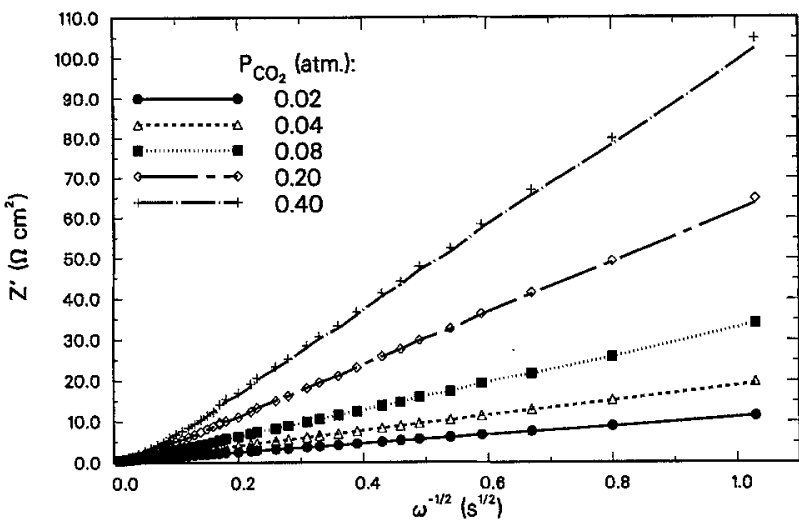

Fig. 3. Effect of $P_{\mathrm{CO}_{2}}$ on $Z^{\prime}$ vs. $\omega^{-1 / 2}$ plot for $\mathrm{O}_{2}$ reduction on gold electrode in $\mathrm{Li}_{2} \mathrm{CO}_{3}$ melt at $0.6 \mathrm{~atm} \mathrm{P}_{\mathrm{O}_{2}}$ and $800^{\circ} \mathrm{C}$; symbols: experimental data; lines: regression data.

a planar gold electrode and the thin film impedance with the Nernst model for a sintered gold electrode to determine the Warburg impedance. Makkus et al. ${ }^{19}$ included the impedance due to homogeneous chemical reaction to resolve the impedance spectra for oxygen reduction in ( $\mathrm{Li}$ $\mathrm{K}) \mathrm{CO}_{3}$ eutectic melt, but the estimated reaction orders for oxygen and carbon dioxide do not agree with the reaction mechanisms proposed in the literature. Tryk and Yeager ${ }^{20}$ have shown the existence of peroxide and superoxide species in the quenched alkali carbonate melts by electron spin resonance spectroscopy and Raman spectroscopy. Tomczyk and Mordarski ${ }^{21}$ studied the oxygen reduction on gold in molten $(\mathrm{Li}+\mathrm{Na}) \mathrm{CO}_{3}$ using linear scan voltammetric and chronoamperometric measurements. Tomczyk and Bieniasz ${ }^{22,23}$ concluded that peroxide species are the dominant species in this melt and the oxygen reduction is controlled by the diffusion of both peroxide and oxide species in the melt. Moutiers et al. ${ }^{24}$ studied the oxygen reduction reaction on gold in $(\mathrm{Na}+\mathrm{K}) \mathrm{CO}_{3}$ eutectic melt at $750^{\circ} \mathrm{C}$. They concluded that molecular oxygen is stabilized in acidic media under a high pressure of carbon dioxide, superoxide species in moderately acidic media, and peroxide species in basic media. Even though these studies have yielded valuable information, the mechanism of oxygen reduction in molten carbonate is still not well understood; furthermore some of the kinetic study results reported in the literature are not consistent with the mechanisms proposed in the literature. The previous studies ${ }^{7-9}$ show that the presence of physically dissolved molecular oxygen in molten carbonate electrolyte is insignificant in moderately acidic and basic media. This is true because oxygen reacts with the molten alkali carbonates to form peroxide and/or superoxide ions, the concentrations of which depend on the cations present in the melt. Thermodynamic data ${ }^{7}$ indicate that the equilibrium concentration of the superoxide ion decreases with a decrease in the ionic radii of the alkali cations (i.e., $\mathrm{C}_{\mathrm{O}_{2}}$ decreases in the order $\mathrm{K}_{2} \mathrm{CO}_{3}>\mathrm{Na}_{2} \mathrm{CO}_{3}>\mathrm{Li}_{2} \mathrm{CO}_{3}$ ), and in a pure lithium carbonate melt the superoxide ion is unstable. Consequently, in this work, we have used a pure lithium carbonate melt to avoid the complexity of simultaneous existence of peroxide and superoxide ions. In our previous work ${ }^{25,26}$ we reported the effects of the partial pressure of oxygen and temperature on electrode kinetics and masstransfer parameters for axygen reduction in pure lithium

Table I. Electrode-kinetic and mass-transfer related parameters estimated by electrochemical impedance spectroscopic technique at $750^{\circ} \mathrm{C}$ temperature and $0.6 \mathrm{~atm} P_{\mathrm{O}_{2}}$.

\begin{tabular}{cccccc}
\hline $\begin{array}{c}P_{\mathrm{CO}_{2}} \\
(\mathrm{~atm})\end{array}$ & $\begin{array}{c}\sigma \\
\left(\Omega \mathrm{cm}^{2} \mathrm{~s}^{-1 / 2}\right)\end{array}$ & $\begin{array}{c}R_{\mathrm{ct}} \\
\left(\Omega \mathrm{cm}^{2}\right)\end{array}$ & $\begin{array}{c}i_{0} \times 10^{3} \\
(\mathrm{~A} \mathrm{~cm})\end{array}$ & $\begin{array}{c}C_{\mathrm{dI}} \times 10^{6} \\
\left(\mathrm{~F} \mathrm{~cm}^{-2}\right)\end{array}$ & $\begin{array}{c}R_{\mathrm{S}} \\
\Omega \mathrm{cm}^{2}\end{array}$ \\
\hline 0.02 & $27.2 \pm 0.66$ & $0.53 \pm 0.06$ & $86.5 \pm 19.3$ & $560 \pm 27.6$ & 0.51 \\
0.04 & $47.1 \pm 0.85$ & $0.66 \pm 0.08$ & $70.1 \pm 17.2$ & $395 \pm 15.9$ & 0.50 \\
0.08 & $82.9 \pm 2.52$ & $1.07 \pm 0.26$ & $43.4 \pm 20.5$ & $313 \pm 17.0$ & 0.38 \\
0.20 & $156 \pm 9.35$ & $2.67 \pm 1.03$ & $17.4 \pm 13.1$ & $271 \pm 18.5$ & 0.36
\end{tabular}


Table II. Electrode-kinetic and mass-transfer related parameters estimated by electrochemical impedance spectroscopic technique at $800^{\circ} \mathrm{C}$ temperature and $0.6 \mathrm{omm} P_{\mathrm{O}_{2}}$.

\begin{tabular}{cccccc}
\hline $\begin{array}{c}P_{\mathrm{CO}_{2}} \\
(\mathrm{~atm})\end{array}$ & $\begin{array}{c}\sigma \\
\left(\Omega \mathrm{cm}^{2} \mathrm{~s}^{-1 / 2}\right)\end{array}$ & $\begin{array}{c}R_{\mathrm{ct}} \\
\left(\Omega \mathrm{cm}^{2}\right)\end{array}$ & $\begin{array}{c}i_{0} \times 10^{3} \\
\left.(\mathrm{~A} \mathrm{~cm})^{-2}\right)\end{array}$ & $\begin{array}{c}C_{\mathrm{dl}} \times 10^{6} \\
\left(\mathrm{~F} \mathrm{~cm}^{-2}\right)\end{array}$ & $\begin{array}{c}R_{\mathrm{S}} \\
\Omega \mathrm{cm}^{2}\end{array}$ \\
\hline 0.02 & $10.3 \pm 0.34$ & $0.25 \pm 0.06$ & $187 \pm 46.2$ & $1250 \pm 83.4$ & 0.50 \\
0.04 & $18.3 \pm 0.52$ & $0.42 \pm 0.09$ & $111 \pm 24.7$ & $729 \pm 41.5$ & 0.53 \\
0.08 & $31.7 \pm 1.06$ & $0.58 \pm 0.18$ & $79.4 \pm 24.6$ & $509 \pm 31.6$ & 0.37 \\
0.20 & $63.2 \pm 1.37$ & $0.84 \pm 0.25$ & $55.3 \pm 16.8$ & $330 \pm 14.1$ & 0.37 \\
0.40 & $100 \pm 4.56$ & $1.43 \pm 0.91$ & $32.3 \pm 20.5$ & $282 \pm 19.3$ & 0.40
\end{tabular}

carbonate melt. The electrode kinetic parameter and masstransfer parameter were determined using electrochemical impedance spectroscopy and cyclic voltammetry techniques. The oxygen reaction order for the exchange current density was determined to be about $0.44 \pm 0.18$ at $850^{\circ} \mathrm{C}$. This value concurs with the theoretical oxygen reaction order of value 0.375 , when the first charge-transfer reaction (Eq. 4) is the rate determining step and the symmetry factor $(\beta)$ has a value of $0.5{ }^{27}$ The oxygen dependence of the reacting species $\left(C_{0}\right)$ was determined to be about 0.5 , which agrees with the peroxide formation reaction (Eq. 3). These results clearly indicate that peroxide is the predominant species in the oxygen reduction process in lithium carbonate melt. In this work, the influence of partial pressure of carbon dioxide on the oxygen reduction kinetics was investigated using electrochemical impedance spectroscopy (EIS) and cyclic voltammetry. Also, the temperature dependence of oxygen reduction kinetic was examined.

\section{Experimental}

The experimental setup for high temperature electrode kinetic study and methodology are as described somewhere else. ${ }^{25}$ The working electrode was made of a submerged gold flag $(0.025 \mathrm{~mm}$ thick), with a geometrical area of one square centimeter, connected to the gold current collector ( $0.5 \mathrm{~mm}$ diam) by a thin gold wire to minimize the meniscus effect. ${ }^{2,17,28}$ The counterelectrode was a large gold foil circumscribing the work electrode to ensure uniform current distribution. The reference electrode was also made of a gold foil but encased in an alumina tube which was pressed against the bottom of the electrochemical cell. The high purity $(99.9 \%)$ gold foils and wires were obtained from Johnson Matthey Group. Digital mass flow controllers/meters manufactured by Teledyne-Hastings Raydist were used to provide the gas mixtures of the desired compositions $\left(\mathrm{O}_{2}, \mathrm{CO}_{2}\right.$, and Ar) with high precision ( $\pm 1 \%$ full scale). The high purity gases were obtained from Matheson Gas Products, and the traces of water were removed by passing the blended gas through a column of $5 \AA$ molecular sieves and Drierite (Fisher Scientific). The gas mixture was bubbled into the melt in the vicinity of the working electrode at a flow rate of $50 \mathrm{~cm}^{3} / \mathrm{min}$ through a long alumina tube with four holes. The composition of the gas mixture supplied to the reference electrode compartment was the same as the one used for the working electrode but at a lower flow rate $\left(5 \mathrm{~cm}^{3} / \mathrm{min}\right)$. In this study, the partial pressure of $\mathrm{CO}_{2}$ was varied from 0.02 to $0.4 \mathrm{~atm}$, while the partial pressure of $\mathrm{O}_{2}$ was maintained constant at $0.6 \mathrm{~atm}$. The total pressure was maintained at $1 \mathrm{~atm}$, by varying the partial pressure of argon. The high purity $(99.999 \%)$ lithium carbonate (Alfa Products) was carefully weighed in an alumina crucible

\section{Table III. Electrode-kinetic and mass-transfer related parameters estimated by electrochemical impedance spectroscopic technique at $850^{\circ} \mathrm{C}$ temperature and $0.6 \mathrm{~atm} P_{\mathrm{O}_{2}}$}

\begin{tabular}{cccccc}
\hline $\begin{array}{c}P_{\mathrm{CO}_{2}} \\
(\mathrm{~atm})\end{array}$ & $\begin{array}{c}\sigma \\
\left(\Omega \mathrm{cm}^{2} \mathrm{~s}^{-1 / 2}\right)\end{array}$ & $\begin{array}{c}R_{\mathrm{ct}} \\
\left(\Omega \mathrm{cm}^{2}\right)\end{array}$ & $\begin{array}{c}i_{0} \times 10^{3} \\
\left(\mathrm{~A} \mathrm{\textrm {cm } ^ { - 2 } )}\right.\end{array}$ & $\begin{array}{c}C_{\mathrm{dd}} \times 10^{6} \\
\left(\mathrm{~F} \mathrm{~cm}^{-2}\right)\end{array}$ & $\begin{array}{c}R_{\mathrm{S}} \\
\Omega \mathrm{cm}^{2}\end{array}$ \\
\hline 0.02 & $4.31 \pm 0.16$ & $0.14 \pm 0.02$ & $337 \pm 75.1$ & $3220 \pm 225$ & 0.51 \\
0.04 & $6.88 \pm 0.23$ & $0.18 \pm 0.02$ & $265 \pm 62.3$ & $1880 \pm 132$ & 0.59 \\
0.08 & $13.3 \pm 0.30$ & $0.27 \pm 0.03$ & $177 \pm 32.5$ & $891 \pm 48.1$ & 0.39 \\
0.20 & $27.0 \pm 0.57$ & $0.47 \pm 0.05$ & $103 \pm 20.1$ & $411 \pm 23.8$ & 0.37 \\
0.40 & $46.2 \pm 1.65$ & $0.71 \pm 0.11$ & $67.8 \pm 20.3$ & $390 \pm 19.3$ & 0.40
\end{tabular}

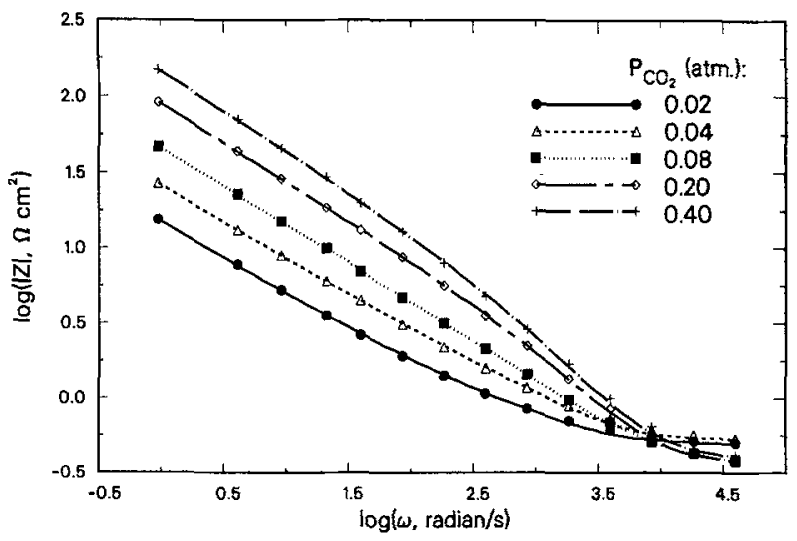

Fig. 4. Effect of $P_{\mathrm{CO}_{2}}$ on $\log |Z|$ vs. $\log \omega$ plot for $\mathrm{O}_{2}$ reduction on gold electrode in $\mathrm{Li}_{2} \mathrm{CO}_{3}$ melt at $0.6 \mathrm{~atm} \mathrm{P}_{\mathrm{O}_{2}}$ and $800^{\circ} \mathrm{C}$; symbols; experimental data; lines: regression data.

(90 $\mathrm{ml}$ capacity) and the electrochemical cell was slowly heated $\left(50^{\circ} \mathrm{C} / \mathrm{h}\right)$ to $350^{\circ} \mathrm{C}$ in an inert environment. The electrochemical cell assembly was dried at $350^{\circ} \mathrm{C}$ in a carbon dioxide environment for $24 \mathrm{~h}$ prior to increasing the temperature to $750^{\circ} \mathrm{C}$.

The data acquisition setup consisting of a potentiostat/ galvanostat (Model 273), lock-in-amplifier (Model 5301A), personal computer (IBM. PS/2), and software (Model 378), obtained from Princeton Applied Research (PAR), was used for the cyclic voltammetric and electrochemical impedance spectroscopic experiments. The EIS measurements were made over a wide range of frequencies $(0.05 \mathrm{~Hz}$ to $10 \mathrm{kHz})$ for the sinusoidal excitation signal ( $5 \mathrm{mV} \mathrm{rms}$ ); the capacitive effect, attributed to the double layer, is significant at high frequency, while the diffusional (Warburg) impedance is dominant at low frequency. The impedance measurements for frequencies higher than $5 \mathrm{~Hz}$ were carried out by the phase sensitive detection (PSD) technique using the lock-in amplifier and the potentiostat. For frequencies below $5 \mathrm{~Hz}$, the cell impedance was measured by the fast Fourier transform (FFT) technique using the personal computer and potentiostat. The results of low frequency measurements (below $5 \mathrm{~Hz}$ ) represent the average values of 15 data cycles, which were necessary to improve the accuracy of the data by averaging out the noise interference. The amplitude of the excitation signal was kept at $5 \mathrm{mV}$ to ensure a linear electrochemical response.

\section{Results and Discussion}

Impedance measurements and analyses.-The impedance spectra, for oxygen reduction on the submerged gold electrode in lithium carbonate melt at the equilibrium potential, were obtained as a function of partial pressure of carbon dioxide and temperature. As described in the previous work, ${ }^{25,26}$ the absence of a semicircle in the complex plane impedance plot indicates fast oxygen reduction $\mathrm{ki}-$ netics. ${ }^{29}$ In the region of low frequency, the complex plane plot showed a linear behavior with a slope of $45^{\circ}$ due to the Warburg impedance. ${ }^{30}$ The effect of partial pressure of carbon dioxide on the Bode plot, phase angle vs. $\log \omega$, at $800^{\circ} \mathrm{C}$ is shown in Fig. 1. In the high frequency region, the phase angle approached $0^{\circ}$ for all plots, indicating a purely resistive behavior of the cell impedance. The impedance at $0^{\circ}$ phase angle is a measure of the uncompensated electrolyte resistance, $R_{\mathrm{S}}$, between the working and the reference electrodes. At frequencies below $30 \mathrm{~Hz}$, the phase angle approached $-45^{\circ}$, indicating that the diffusional impedance is significant. The influence of partial pressure of carbon dioxide on oxygen reduction kinetics is evident at the intermediate frequencies, i.e., the charge-transfer resistance increases with increase of $P_{\mathrm{CO}_{2}}$. The sharp deviations in the Bode plots at about $120 \mathrm{~Hz}(\log \omega \cong 2.9)$ cannot be explained at this time. It may be possible that a flaw exists in the experimental equipment. The impedance spectra were resolved by using the Randles-Ershler equivalent circuit ${ }^{31,32}$ model shown in Fig. 2. The Randles-Ershler equivalent 
Table IV. Comparison of product $D_{\mathrm{O}}^{1 / 2} C_{\circ}$ estimated by cyclic voltammetry and electrochemical impedance spectroscopy at $0.2 \mathrm{~atm} P_{\mathrm{co}_{2}}$.

\begin{tabular}{|c|c|c|c|c|c|c|}
\hline \multirow{3}{*}{$\begin{array}{c}\text { Temperature } \\
{ }^{\circ} \mathrm{C} \\
P_{\mathrm{CO}_{2}} \\
(\mathrm{~atm})\end{array}$} & \multicolumn{4}{|c|}{$\begin{array}{c}D_{\circ}^{1 / 2} C_{O} \times 10^{9} \\
\left(\mathrm{~mol} \mathrm{~cm}^{-2} \mathrm{~s}^{-1 / 2}\right)\end{array}$} & & \\
\hline & \multicolumn{2}{|c|}{750} & \multicolumn{2}{|c|}{800} & \multicolumn{2}{|c|}{850} \\
\hline & $\begin{array}{c}\text { Cyclic } \\
\text { voltammetry }\end{array}$ & $\begin{array}{l}\text { Impedance } \\
\text { analysis }\end{array}$ & $\begin{array}{c}\text { Cyclic } \\
\text { voltammetry }\end{array}$ & $\begin{array}{c}\text { Impedance } \\
\text { analysis }\end{array}$ & $\begin{array}{c}\text { Cyclic } \\
\text { voltammetry }\end{array}$ & $\begin{array}{c}\text { Impedance } \\
\text { analysis }\end{array}$ \\
\hline 0.02 & 5.67 & $5.93 \pm 0.15$ & 15.6 & $16.4 \pm 0.54$ & 38.8 & $41.1 \pm 1.48$ \\
\hline 0.04 & 3.32 & $3.43 \pm 0.06$ & 9.24 & $9.25 \pm 0.26$ & 24.9 & $25.8 \pm 0.84$ \\
\hline 0.20 & 1.06 & $1.04 \pm 0.07$ & 2.53 & $2.68 \pm 0.06$ & 6.12 & $6.60 \pm 0.14$ \\
\hline 0.40 & 0.68 & & 1.55 & $1.65 \pm 0.07$ & 3.61 & $3.84 \pm 0.14$ \\
\hline
\end{tabular}

circuit reflects two parallel processes occurring at the electrode-electrolyte interface, namely, the double layer charging and the faradaic reaction. The faradaic impedance consists of the charge-transfer resistance which is in series with the Warburg (diffusional) impedance. The uncompensated electrolyte resistance between the working and reference electrodes, $R_{\mathrm{S}}$, is connected in series with the interfacial impedance. A complex nonlinear least squares (CNLS) parameter estimation program, ${ }^{33-35}$ based on LevenbergMarquardt algorithm, was used to resolve the impedance spectra. In our analysis, we found that the weighting factor (inverse of the error variance) considerably influenced the accuracy of the parameters estimated from the impedance data. ${ }^{25}$ Here, we have used the proportional (PWT) and functional proportional weighting (FPWT) factors ${ }^{36}$ to determine the electrode-kinetic and the mass-transfer parameters. This analysis yields parameters such as the charge-transfer resistance, double-layer capacity, Warburg coefficient, and uncompensated electrolyte resistance. The parameter estimation by the complex nonlinear least squares method also provides the standard deviation of the estimated parameters.

The effects of partial pressure of carbon dioxide on real part of impedance $\left(Z^{\prime}\right) v s$. inverse square root of angular frequency $\left(\omega^{-1 / 2}\right)$ at $800^{\circ} \mathrm{C}$ temperature is shown in Fig. 3 . In the low frequency region, $Z^{\prime}$ vs. $\omega^{-1 / 2}$ plots showed a linear behavior and the slope of this line is proportional to the Warburg coefficient $(\sigma){ }^{37}$ As demonstrated in Fig. 3 , the Warburg coefficient increases with increase of $P_{\mathrm{CO}_{2}}$. This result can be rationalized easily because with increase of $P_{\mathrm{CO}_{2}}$, there is a decrease in the peroxide ion concentration (Eq. 3) and the Warburg coefficient is inversely proportional to the concentration of this diffusing species. The electrode-kinetic and mass-transfer parameters as function of $P_{\mathrm{CO}_{2}}$, for temperatures 750,800 , and $850^{\circ} \mathrm{C}$, are presented in Tables I-III, respectively. The predicted impedance values in Fig. 3, calculated using the estimated parameter values given in Tables I-III and the RandlesErshler equivalent circuit model, agreed well with the experimental data. As shown in these tables, a decrease in $P_{\mathrm{CO}_{2}}$ from 0.4 to $0.02 \mathrm{~atm}$ caused a ten-fold decrease in the

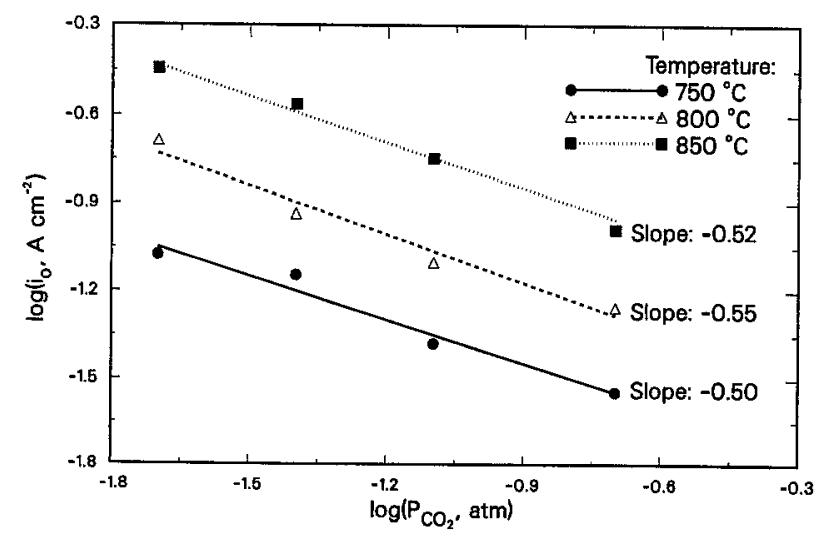

Fig. 5. Plots of $\log i_{0}$ vs. $\log P_{\mathrm{CO}_{2}}$ for $\mathrm{CO}_{2}$ reaction orders determination at $0.6 \mathrm{~atm} P_{\mathrm{O}_{2}}$ symbols: experimental data; lines: regression data. magnitude of the Warburg coefficient. A similar trend was observed when the temperature was increased from 750 to $850^{\circ} \mathrm{C}$. The charge-transfer resistance also decreased with increase in temperature and decrease in partial pressure of carbon dioxide. The double layer capacity for the smooth gold electrode in a pure lithium carbonate melt was much higher than that observed for a smooth electrode in an aqueous electrolytes. Also the double layer capacity increased with decrease in $P_{\mathrm{CO}_{2}}$, and this increase was more significant at higher temperature. This dependence of double layer capacity on temperature and on $P_{\mathrm{CO}_{2}}$ cannot be explained completely at this point, but it may be due to the formation of a solid oxide layer on the electrode. The change in the uncompensated electrolyte resistance with temperature and $P_{\mathrm{CO}_{2}}$ is negligible. The effects of partial pressure of carbon dioxide on the $\log |Z|$ vs. $\log \omega$ plot is shown in Fig. 4. The $|Z|$ vs. log $\omega$ plot converged to the value of uncompensated electrolyte resistance at high frequencies. In the low frequency region, complete relaxation of the charge-transfer process was not observed due to the diffusion-related impedance. Also, it is evident from Fig. 4 that the experimental data concurred with the model predictions for the entire frequency range of the experiment. Since impedance measurements were obtained at the rest potential, the following expressions were used for calculations of the charge-transfer resistance and the Warburg coefficient $^{37}$

$$
\begin{gathered}
R_{\mathrm{ct}}=\frac{R T}{n F i_{0}} \\
\sigma=\frac{R T}{n^{2} F^{2} A \sqrt{2}}\left(\frac{1}{D_{\circ}^{1 / 2} C_{\mathrm{O}}}+\frac{1}{D_{\mathrm{R}}^{1 / 2} C_{\mathrm{R}}}\right)
\end{gathered}
$$

As shown in Eq. 5 and 6 , the products of the electrochemical reduction are believed to be either $\mathrm{O}^{2-}$ or $\mathrm{CO}_{3}^{2-}$, depending on the kinetics of the homogeneous recombination reaction. Carbonate concentration in the melt is obviously larger than the peroxide concentration. Based on the thermodynamic data, ${ }^{7}$ the concentration of oxide is at least three orders of magnitude higher than that of peroxide for all gas compositions used. ${ }^{17}$ Hence, concentration of the product $\left(C_{\mathrm{R}}\right.$, where $\mathrm{R}=\mathrm{O}^{2-}$ or $\left.\mathrm{CO}_{3}^{2-}\right)$ in the melt is much larger than the concentration of the peroxide ions $\left(C_{0}\right)$. Considering that $D_{O}$ and $D_{R}$ are of same order of magnitude, then $1 /\left(D_{R}^{1 / 2} C_{R}\right)$ is negligible compared with $1 /\left(D_{\mathrm{O}}^{1 / 2} C_{\mathrm{O}}\right)$, provided. Thus Eq. 9 can be approximated by the following expression

$$
\sigma=\frac{R T}{n^{2} F^{2} A \sqrt{2}}\left(\frac{1}{D_{\mathrm{O}}^{1 / 2} C_{\mathrm{O}}}\right)
$$

The calculated values of the exchange current density and parameter, $D_{\mathrm{O}}^{1 / 2} C_{\mathrm{O}}$, as functions of $P_{\mathrm{CO}_{2}}$ and temperature, are given in Table IV. The increase in partial pressure of carbon dioxide, decreased the electrode kinetics, for example, the exchange current density decreased more than five fold when the partial pressure of carbon dioxide was increased from 0.02 to $0.4 \mathrm{~atm}$. As shown in Fig. 5, a plot of $\log i_{0} v \mathrm{~s}$. $\log P_{\mathrm{CO}_{2}}$ showed a linear behavior when $P_{\mathrm{CO}_{2}}$ was varied from 0.02 to $0.2 \mathrm{~atm}$; the carbon dioxide reaction order was negative, and the value was about -0.52. As shown in Table V, the theoretical reaction order is -1.25 , when the first charge-transfer step (Eq. 4) is considered to be the 
Table V. The reaction order with respect to carbon dioxide for the exchange current density and $D_{0}^{1 / 2} C_{0}$ estimated by cyclic voltammetric and electrochemical impedance spectroscopic techniques.

\begin{tabular}{|c|c|c|c|c|}
\hline Parameter & Technique & $\begin{array}{l}\text { Temperature } \\
\left({ }^{\circ} \mathrm{C}\right)\end{array}$ & $\begin{array}{l}\text { Estimated } \mathrm{CO}_{2} \\
\text { reaction order }\end{array}$ & $\begin{array}{c}\text { Theoretical } \mathrm{CO}_{2} \\
\text { reaction order }\end{array}$ \\
\hline$D_{\mathrm{O}}^{1 / 2} C_{\mathrm{O}}$ & $\begin{array}{l}\text { Electrochemical impedance spectroscopy } \\
\text { Cyclic voltammetry }\end{array}$ & $\begin{array}{l}750 \\
800 \\
850 \\
750 \\
800 \\
850\end{array}$ & $\begin{array}{l}-0.77 \pm 0.08 \\
-0.77 \pm 0.04 \\
-0.80 \pm 0.06 \\
-0.71 \pm 0.06 \\
-0.78 \pm 0.05 \\
-0.81 \pm 0.08\end{array}$ & -1.00 \\
\hline
\end{tabular}

rate-determining step and the symmetry factor $\beta$ is $0.5 .^{27}$ Thus, the reaction order of the exchange current density with respect to carbon dioxide does not agree well with the theoretically expected value for the above mentioned ratecontrolling charge-transfer step. This discrepancy in the carbon dioxide reaction order may then be due to slow kinetics of a homogeneous recombination reaction (Eq. 6). The Arrhenius plots for the exchange current density are shown in Fig. 6 for $P_{\mathrm{CO}_{2}}$ ranging from 0.02 to $0.2 \mathrm{~atm}$. The activation energy was calculated to be $131.8 \mathrm{~kJ} / \mathrm{mol}$; this value is consistent with the value obtained in the previous work. ${ }^{26}$ The plots of $\log D_{0}^{1 / 2} C_{O}$ vs. $\log P_{\mathrm{CO}_{2}}$, for three different temperatures and $P_{\mathrm{CO}}$ ranging from 0.02 to $0.2 \mathrm{~atm}$, are shown in Fig. 7; the value of the reaction order with respect to carbon dioxide calculated from the slopes of these plots is about -0.8 . As shown in Table $V$, the estimated reaction order for peroxide ions agreed well with the theoretical dependence of peroxide concentration on partial pressure of carbon dioxide. The Arrhenius plots for $D_{0}^{1 / 2} C_{0}$ for four partial pressures of carbon dioxide are shown in Fig. 8; the average value of the apparent activation energy was determined to be $185 \mathrm{~kJ} / \mathrm{mol}$.

Cyclic voltammetry--Cyclic voltammetric measurements were made for oxygen reduction on a gold electrode in a quiescent $\mathrm{Li}_{2} \mathrm{CO}_{3}$ melt as a function of the scan rate, temperature, and $P_{\mathrm{CO}_{2}}$. The working electrode potential was scanned between the rest potential $(0.0 \mathrm{~V})$ and $-0.5 \mathrm{~V}$ $v s$. the potential of the reference electrode; the scan rate was varied from 10 to $200 \mathrm{mV} / \mathrm{s}$. The reference electrode was exposed to the same gas composition as that for the working electrode. The effects of $P_{\mathrm{CO}_{2}}$ on the cyclic voltammogram, recorded at a scan rate of $100 \mathrm{mV} / \mathrm{s}$ and at $800^{\circ} \mathrm{C}$ temperature is shown in Fig. 9. During the forward scan, a diffusion-limited peak followed by a limiting plateau was observed. The peak potential $\left(E_{\mathrm{P}}\right)$ was found to be independent of the scan rate (up to $200 \mathrm{mV} / \mathrm{s}$ ) and the position of this peak corresponds to $R T / 2 F$ negative to the rest potential, indicating that two electrons are involved in the oxygen reduction in a pure lithium carbonate melt. As shown in Fig. 9, an increase in partial pressure of carbon dioxide decreased the cathodic peak current density. The

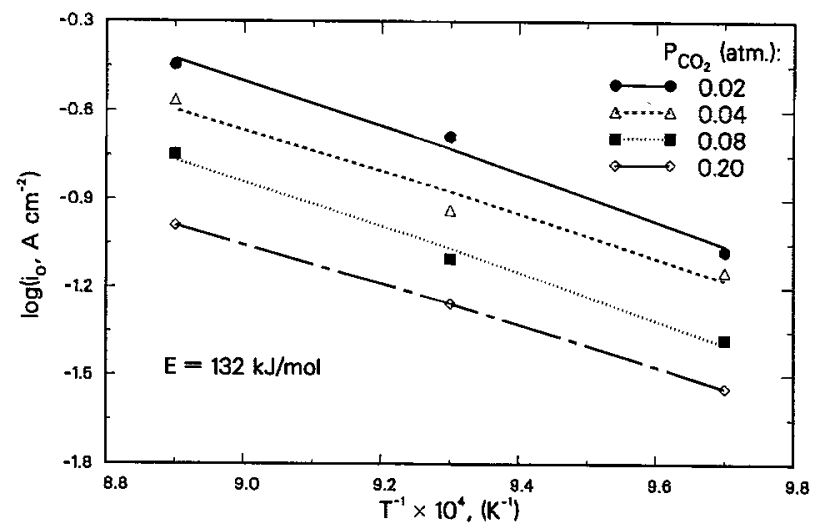

Fig. 6. Plots of $\log i_{0} v s . T^{-1}$ for determination of activation energy at $0.6 \mathrm{~atm} P_{\mathrm{O}_{2}}$ symbols: experimental data; lines: regression data. current densities in the reverse scan were less cathodic than those obtained in the forward sweep. At the end of the sweep, a large anodic current was observed which subsided slowly and reached a zero value in a few minutes. As mentioned earlier, the products of the electrochemical reduction of peroxide are either carbonate or oxide ions. Both carbonate and oxide ions have a much larger concentration in the melt compared to that of peroxide. Hence, both products of the electrochemical reaction can be assumed at limitingly high concentrations and invariant. According to Berzins and Delahay, ${ }^{38}$ the peak current density for such a system is defined by the following expression

$$
i_{\mathrm{p}}=0.61 \frac{(n F)^{3 / 2}}{(R T)^{1 / 2}} C_{\mathrm{O}} D_{\bigcirc}^{1 / 2} v^{1 / 2}
$$

According to Eq. 11, a plot of the experimental values of $i_{\mathrm{p}}$ $v s . v^{1 / 2}$ should be linear, and the slope may be used to obtain the product $D_{0}^{1 / 2} C_{\mathrm{o}}$. As shown in Fig. 10, a plot of $i_{\mathrm{p}} v s . v^{1 / 2}$ is linear. A linear behavior of $i_{\mathrm{p}} v s . v^{1 / 2}$ and invariance of $E_{\mathrm{p}}$ with respect to the scan rate indicated that the oxygen reduction in $\mathrm{Li}_{2} \mathrm{CO}_{3}$ melt is "reversible" up to $200 \mathrm{mV} / \mathrm{s}$. The effects of $P_{\mathrm{CO}_{2}}$ on the peak current density $\left(i_{\mathrm{p}}\right) v s$. square root of the scan rate $\left(v^{1 / 2}\right)$ plot at $800^{\circ} \mathrm{C}$ are shown in Fig. 10. An increase in partial pressure of carbon dioxide decreased the slope of $i_{\mathrm{p}} v s . v^{1 / 2}$ plot, because the slope is directly proportional to $D_{0}^{1 / 2} C_{0}$, where $D_{0}$ is the diffusion coefficient and $C_{O}$ is the bulk concentration of the diffusion limiting reactant species, peroxide ion. According to Eq. 3, bulk concentration of peroxide decreases with an increase in the partial pressure of carbon dioxide. The product, $D_{0}^{1 / 2} C_{\mathrm{O}}$, was calculated from the slope of $i_{\mathrm{p}} v s . v^{1 / 2}$ plot using Eq. 11. As shown in Table IV, the calculated values of the transport parameter for various $P_{\mathrm{CO}_{2}}$ and temperatures agreed with those estimated by the electrochemical impedance spectroscopy. An increase in partial pressure of carbon dioxide decreases the product $D_{\mathrm{O}}^{1 / 2} C_{\mathrm{O}}$, which is mainly due to the decrease in peroxide ion concentration. Temperature has a significant effect on the product, $D_{O}^{1 / 2} C_{O}$, for example, for $0.02 \mathrm{~atm}$ partial pressure of carbon dioxide, almost an order of magnitude increase in $D_{0}^{1 / 2} C_{0}$ was observed when

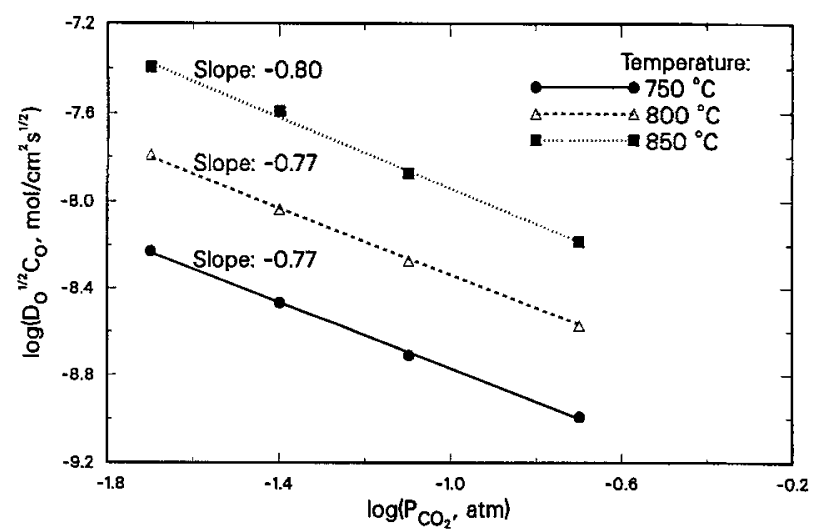

Fig. 7. Plots of $\log D_{\mathrm{O}}^{1 / 2} C_{\mathrm{O}}$ vs. $\log \mathrm{P}_{\mathrm{O}_{2}}$ for $\mathrm{O}_{2}$ reaction orders determination at $0.2 \mathrm{~atm} P_{\mathrm{CO}_{2},} D_{\mathrm{O}}^{1 / 2} \mathrm{C}_{\mathrm{O}}$ estimated by impedance analysis; symbols: experimental data; lines: regression data. 


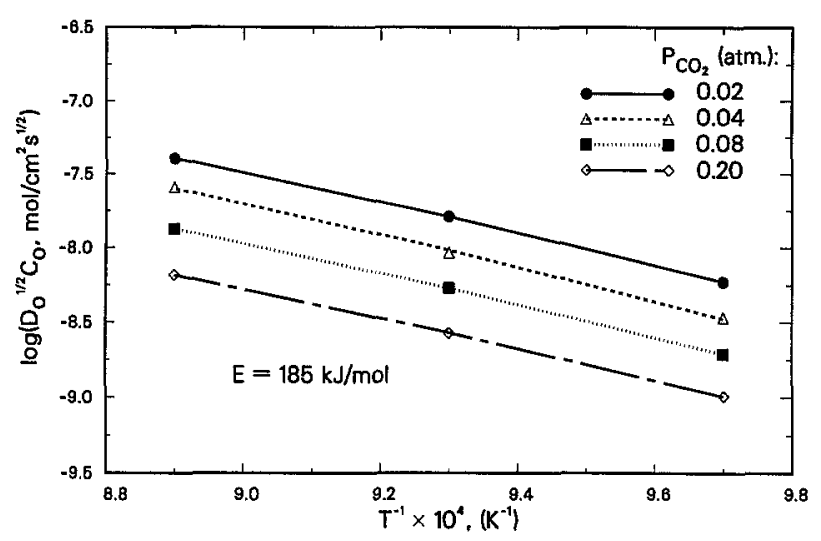

Fig. 8. Plots of $\log D_{0}^{1 / 2} C_{O}$ vs. $T^{-1}$ for determination of activation energy at $0.6 \mathrm{~atm} \mathrm{P}_{\mathrm{O}_{2}}, D_{0}^{1 / 2} C_{0}$ estimated by impedance analysis; symbols: experimental data; lines: regression data.

temperature was increased from 750 to $850^{\circ} \mathrm{C}$. However, the influence of temperature on $D_{0}^{1 / 2} C_{0}$ was less significant at higher $P_{\mathrm{CO}_{2}}$. As shown in Table $\mathrm{V}$, the reaction order and apparent activation energy for $D_{0}^{1 / 2} C_{O}$, estimated using cyclic voltammetry technique, concurred with those obtained by impedance analysis.

\section{Conclusions}

The kinetic and mass-transfer related parameters for the oxygen reduction in pure $\mathrm{Li}_{2} \mathrm{CO}_{3}$ were determined as a function of $P_{\mathrm{CO}_{2}}$ and temperature by electrochemical impedance spectroscopy and cyclic voltammetry. The impedance spectra were analyzed by the Randles-Ershler equivalent circuit model using a complex nonlinear least squares parameter estimation technique. The impedance data analysis yielded the electrode-kinetic and mass-trans-

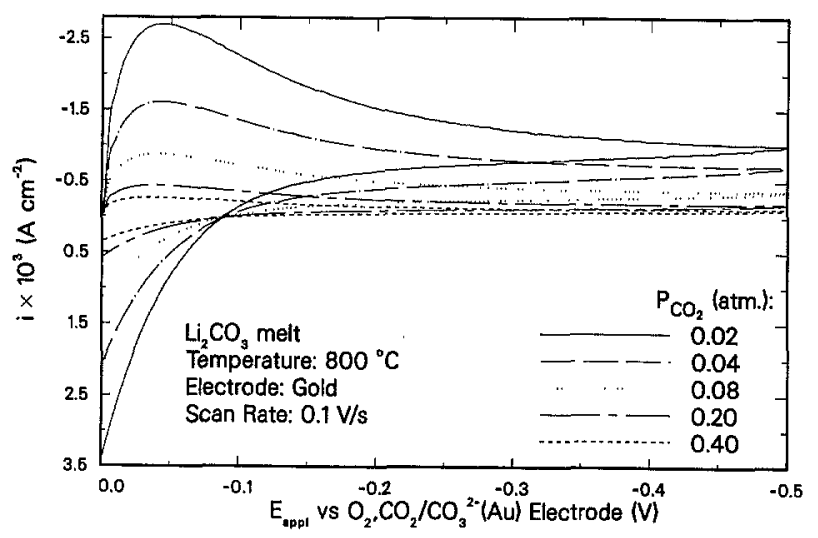

Fig. 9. Effect of $P_{\mathrm{CO}_{2}}$ on cyclic voltammogram for $\mathrm{O}_{2}$ reduction at $0.6 \mathrm{~atm} P_{\mathrm{O}_{2}}$, reference and working gases have same composition.

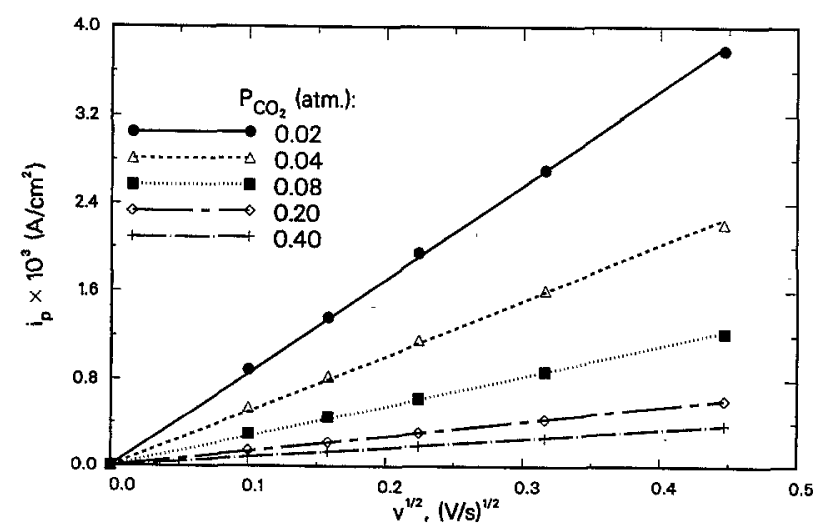

Fig. 10. Effect of $P_{\mathrm{CO}_{2}}$ on $i_{\mathrm{p}}$ vs. $v^{1 / 2}$ plot for $\mathrm{O}_{2}$ reduction on gold electrode in $\mathrm{Li}_{2} \mathrm{CO}_{3}$ melt at $0.6 \mathrm{~atm} \mathrm{P}_{\mathrm{O}_{2}}$ and $800^{\circ} \mathrm{C}$; symbols: experimental data; lines: regression data. fer parameters such as the charge-transfer resistance, Warburg coefficient, double layer capacitance, and uncompensated solution resistance. The influence of carbon dioxide on the Warburg coefficient was examined and its reaction order was estimated to be about -0.8 , which was consistent with the theoretical value of -1.0 for the formation of peroxide species $(\mathrm{Eq}, .3)$. The values for $D_{\mathrm{O}}^{1 / 2} C_{0}$ obtained by impedance analysis and by cyclic voltammetry agree well. The decrease in the exchange current density with increase in partial pressure of carbon dioxide is due to the decrease in the concentration of peroxide ions with an increase in the partial pressure of carbon dioxide (Eq. 3). The carbon dioxide reaction order for the exchange current density was estimated to be -0.52 . This does not agree with the predicted theoretical reaction order of -1.25 when the first charge-transfer reaction (Eq. 4) is considered to be the rate-determining step. This disagreement in the reaction order may be due to slow neutralization kinetics (Eq. 5), since the partial pressure of carbon dioxide was as low as $0.02 \mathrm{~atm}$. The activation energy for the exchange current density was determined to be about $132 \mathrm{~kJ} / \mathrm{mol}$. Also, the reaction order with respect to carbon dioxide and the activation energy for $D_{0}^{1 / 2} C_{0}$ were calculated to be -0.8 and 185 $\mathrm{kJ} / \mathrm{mol}$, respectively.

The study of a diffusion-controlled peak indicates that the oxygen reduction reaction is "reversible" up to $200 \mathrm{mV} / \mathrm{s}$, the peak potential was found to be independent of the scan rate and the peak current density was proportional to the square root of the scan rate. Since the peak potential was observed to be $R T / 2 F(45-50 \mathrm{mV})$ negative to the equilibrium potential, oxygen reduction involves a two-electron transfer. The carbon dioxide dependence of the diffusion-controlled peak was determined to be -0.8 . The dependence of the diffusion-controlled peak on partial pressure of oxygen was determined to be +0.5 by cyclic voltammetry and EIS techniques in the previous work. ${ }^{25}$ These results clearly indicate that the oxygen reduction reaction on a submerged gold electrode in a pure lithium carbonate is diffusion controlled and the peroxide is the diffusing species. The temperature dependence of the diffusion-controlled peak was also examined and the activation energy was calculated to be about $176.6 \mathrm{~kJ} / \mathrm{mol}$; this activation energy value agreed with that obtained from EIS data.

\section{Acknowledgment}

Financial support for this project from the U.S. Department of Energy (Contract No. DE-FG22-87PC79931) and Electric Power Research Institute (Contract No. RP8002-7) is gratefully acknowledged.

Manuscript submitted April 24, 1991; revised manuscript received March 21, 1993.

Texas A\&M University assisted in meeting the publication costs of this article.

\section{LIST OF SYMBOLS}

A electrode area, $\mathrm{cm}^{2}$

$C_{\mathrm{d} 1}$ double layer capacitance, $\mu \mathrm{F} / \mathrm{cm}^{2}$

$C_{\mathrm{i}}$ bulk concentration of species $j, \mathrm{~mol} / \mathrm{cm}^{3}$

$D_{i}$ bulk diffusion coefficient of species $j, \mathrm{~cm}^{2} / \mathrm{s}$

$E_{\mathrm{p}}$ peak potential, V

$F$ Faraday's constant, $96,487 \mathrm{C}$ /equiv.

$i$ current density, $\mathrm{A} / \mathrm{cm}^{2}$

$i_{0}$ exchange current density, $\mathrm{A} / \mathrm{cm}^{2}$

$i_{\mathrm{p}}$ peak current density, $\mathrm{A} / \mathrm{cm}^{2}$

$n$ number of electrons transferred in electrode reaction

$P$ pressure, atm

$R$ universal gas constant, $8.3143 \mathrm{~J} \mathrm{~mol}^{-1} \mathrm{~K}^{-1}$

$R_{\text {ct }}$ charge-transfer resistance, $\Omega \mathrm{cm}^{2}$

$R_{\mathrm{S}}$ solution resistance, $\Omega \mathrm{cm}^{2}$

$T$ temperature, $\mathrm{K}$

$v$ scan rate, $\mathrm{V} / \mathrm{s}$

$Z \quad$ impedance, $\Omega \mathrm{cm}^{2}$

$|Z|$ modulus of impedance, $\Omega \mathrm{cm}^{2}$

Greek

$\sigma \quad$ Warburg coefficient, $\Omega \mathrm{cm}^{2} \mathrm{~s}^{-1 / 2}$

$\phi$ phase angle

$\omega$ angular frequency, radian/s 
Superscripts

real part of impedance

imaginary part of impedance

Subscripts

$\mathrm{O}$ peroxide or superoxide ions

$R$ carbonate ions

\section{REFERENCES}

1. A. Borucka and C. M. Sugiyama, Electrochim. Acta, 13, 1887 (1968).

2. A. Borucka and C. M. Sugiyama, ibid., 14, 871 (1969).

3. A. J. Appleby and S. B. Nicholson, J. Electroanal. Chem., 38, App. 14 (1972).

4. A. J. Appleby and S. B. Nicholson, ibid. , 53, 105 (1974).

5. A. J. Appleby and S. B. Nicholson, ibid., 83, 309 (1977).

6. A. J. Appleby and S. B. Nicholson, ibid., 112, 71 (1980).

7. B. Kr. Andersen, Ph.D. Dissertation, The Technical University of Denmark Lyngby, Denmark (1975).

8. A. J. Appleby and C. Van Drunen, This Journal, 127, 1655 (1980).

9. W. M. Vogel, S. W. Smith, and L. J. Bregoli, ibid., 130, 575 (1983).

10. S. W. Smith, W. M. Vogel, and S. Kapelner, ibid., 129, 1668 (1982).

11. G. B. Dunks and D. Stelman, Inorg. Chem., 22, 2168 (1983).

12. S. H. Lu, Ph.D. Dissertation, Illinois Institute of Technology, Chicago, IL (1985).

13. I. Uchida, T. Nishina, Y. Mugikura, and K. Itaya, $J$. Electroanal. Chem., 206, 229 (1986).

14. I. Uchida, T. Nishina, Y. Mugikura, and K. Itaya, ibid., 206, 241 (1986).

15. I. Uchida, T. Nishina, Y. Mugikura, and K. Itaya, ibid., 209, 125 (1986)

16. P. K. Adanuvor, R. E. White, and A. J. Appleby, This Journal, 137, 2095 (1990).

17. K. Ramaswami, Ph.D. Dissertation, Illinois Institute of Technology, Chicago, IL (1990).

18. T. Nishina and I. Uchida, in Molten Carbonate Fuel Cells, J. R. Selman, I. Uchida, and D. A. Shores, Edi- tors, PV 90-16, p. 438, The Electrochemical Society Softbound Proceedings Series, Pennington, NJ (1990).

19. R. C. Makkus, K. Hemmes, and J. H. W. de Wit, ibid., p. 454 .

20. D. A. Tryk and E. B. Yeager, ibid., p. 395.

21. P. Tomczyk and G. Mordarski, J. Electroanal. Chem., 304, 85 (1991).

22. L. K. Bieniasz, J. Electroanal. Chem., 304, 101 (1991)

23. P. Tomczyk and L. K. Bieniasz, ibid., 304, 111 (1991).

24. G. Moutiers, M. Cassir, C. Piolet, and J. Devynck, Electrochim. Acta, 36, 1063 (1991).

25. B. B. Dave', R. E. White, S. Srinivasan, and A. J. Appleby, This Journal, 138, 673 (1991).

26. B. B. Dave', R. E. White, S. Srinivasan, and A. J. Appleby, ibid., 138, 2675 (1991).

27. B. B. Dave', Ph.D. Dissertation, Texas A\&M University, College Station, TX (1991).

28. T. Nishina, M. Takahashi, and I. Uchida, ibid., 137, $1112(1990)$

29. R. De Levie and L. Pospisil, J. Electroanal. Chem., 22, 277 (1969).

30. E. Warburg, Ann. Phys. Chem., 67, 493 (1899).

31. J. E. B. Randles, Discuss. Faraday Soc., 1, 11 (1947).

32. B. Ershler, ibid., 1, 269 (1947).

33. J. R. Macdonald, J. Electroanal. Chem., 223, 25 (1987)

34. J. R. Macdonald, in Impedance Spectroscopy-Emphasizing Solid Material and Systems, J. R. Macdonald, Editor, p. 1, John Wiley \& Sons, Inc., New York (1987).

35. J. R. Macdonald, Electrochim. Acta, 35, 1483 (1990).

36. J. R. Macdonald and L. D. Potter, Jr., Solid State Ionies, $\mathbf{2 3}, 61$ (1987)

37. M. Sluyters-Rehbach and I. H. Sluyters, in Electroanalytical Chemistry, Vol. 4, A. J. Bard, Editor, p. 1, Marcel Dekker, Inc., New York (1970).

38. T. Berzins and P. Delahay, J. Am. Chem. Soc., 75, 555 (1953).

39. R. S. Nicholson and I. Shain, Anal. Chem., 36, 706 (1964).

\title{
Electrochemical Oxidations of Several Organic Compounds in Aqueous Surfactant Suspensions Using Higher Valence Oxides as Intermediates
}

\author{
Thomas C. Franklin, ${ }^{*}$ Remi Nnodimele, and Josef Kerimo \\ Department of Chemistry, Baylor University, Waco, Texas 76798-7348
}

\section{ABSTRACT}

Copper(II) oxide and manganese(II) oxide were shown to be catalysts for the electro-oxidation of 2-chloroethyl ethyl sulfide, diethylsulfide, 2-hydroxyethyl ethyl sulfide, and 1-chlorobutane in aqueous suspensions containing cationic surfactants. These oxides were shown to act as catalysts by formation of copper(III), manganese(III), and manganese(IV) oxides which chemically oxidized the organic compounds. Analysis of the product suspensions showed the production of only the sulfoxide by oxidation of the 2-chloroethyl ethyl sulfide and diethyl sulfide. Destruction of chlorobutane was catalyzed by both barium peroxide and copper(II) oxide. Volatile product(s) was trapped in a liquid nitrogen trap during electrolysis. These products included butane and butene.

In previously published studies, it was shown that a number of insoluble, difficulty oxidizable inorganic compounds could be electrolytically oxidized in aqueous cationic surfactant systems ${ }^{1-6}$ because the surfactant solubilized the compounds and formed hydrophobic films on the electrode excluding water from the surface thus raising the oxidation potential of water by $0.9-1.7 \mathrm{~V}$. This allowed application of much higher potentials without interference from the competing process, the destruction of water. Partially because of the ability to extend the potential available in aqueous solutions to do oxidations, it has been pos-

* Electrochemical Society Active Member. sible to electro-oxidize a variety of insoluble inorganic compounds to higher oxidation states, ${ }^{4-6}$ some of which are normally unstable in aqueous systems. These unstable compounds are probably stabilized by their formation as insoluble compounds and by the formation on the compounds of a hydrophobic film of the surfactant which inhibits their reaction with water; thus they have time to react with organic compounds suspended in the water in surfactant micelles. Studies have been initiated on the use of the oxidized states to oxidize different organic compounds. ${ }^{7-9}$

Earlier reported work ${ }^{7-9}$ was on the oxidation of barium peroxide to an active intermediate, concluded to be the 